\section{Practical Considerations of the FTT Device for Fabric Comfort Evaluation}

\section{Binti Haji Musa $\mathrm{A}^{1,3^{*}}$, Malengier $\mathrm{B}^{1}$, Vasile $\mathrm{S}^{2}$ and Van Langenhove $\mathrm{L}$}

\begin{abstract}
The Fabric Touch Tester (FTT) is a device used to measure fabric handle properties. Since the device is considerably new in the market, no standard is available for now and the only reference for users is the brief guidelines by the manufacturer. Having done the experiments for more than 100 types of samples on FTT, the gathered experiences are reported in this paper including the handling of the device, possible analysis to be performed with the FTT data and other possible tests on fabric comfort related matters. We found that extensive care is needed to verify the accuracy of the device sensors, reference samples must be acquired, and a different test setup is required. The default comfort models also must be controlled using panel testing when testing new types of fabrics, and replaced with own models if needed. Apart from these, the FTT is a very useful addition towards fast and reliable comfort testing.
\end{abstract}

\section{Keywords}

Fabric touch tester; Comfort; Hand; Touch

\section{Introduction}

The Fabric Touch Tester (FTT) (Figure 1) is relatively new equipment manufactured by SDL ATLAS, developed in collaboration with a team of researchers at The Hong Kong Polytechnic University. This device is used to measure the fabric handle in less than five minutes per sample. Within its four modules, bending, compression, surface and thermal properties are concomitantly measured, resulting in 13 fabric indices as listed in Table 1. The measurements are comprehensive and cover both sides (inside and outside of the fabric) and both directions (warp/wale and weft/coarse). Based on obtained values of the 13 fabric indices, the FTT software will subsequently compute three primary comfort indices i.e. smoothness, softness and warmness, as well as two global comfort indices i.e. total hand and total touch. Details about the modules of the instrument and calculation of the fabric indices have been reported elsewhere [1-3]. The device also makes distinction between the active and passive primary and global comfort indices where the active measurement is always the sensorial touch with fingers on the fabric face or outside, while passive refers to the feel when wearing the fabric which is on the

*Corresponding author: Binti Haji Musa A, Ghent University, Centre of Textile Science and Engineering, Department of Materials, Textiles and Chemical Engineering, Technologiepark 907, 9052 Zwijnaarde (Gent), Belgium. Tel: +09 264 58 30, Fax: 0926458 32; E-mail: atiyyah.bintihajimusa@ugent.be

Received: November 29, 2017 Accepted: January 13, 2018 Published: January 18,2018 inside of the fabric sample. The prediction models of comfort indices were developed by the FTT manufacturer and they are not publicly available, though once sufficient tests have been done with the FTT, the model coefficients can be determined via statistical analysis as a linear model is used.

In the Centre for Textile and Engineering Science, Ghent University, Belgium, the FTT has been used extensively for fabric comfort testing within the Touché project (Boosting Innovation Through Application of Basic Understanding of the Process and Testing of Textile Touch and Fabric Feel). Through this project, FTT was found to be sensitive enough to discriminate between fabrics for protective clothing with comparable mass per unit area or thickness [4]. Moreover, it could distinguish between tactile properties of the cellulosic fabrics (e.g. Tencel ${ }^{\star}$, Modal) and FTT comfort indices (e.g. softness, smoothness) were in good agreements with the expert panels and Tissue Softness Analyzer (TSA) [5]. The reliability of the device thickness and bending measurement was also analyzed in comparison with the standard method as reported by Binti Haji Musa et.al [6]. A recent study by Vasile et al. $[7,8]$ also testified the ability of the FTT to discriminate between FTT primary comfort indices of knitted fabrics differentiated by treatments and type of yarns used. Nevertheless, since the device has only recently been introduced in the market, the only guidelines available are those from the manufacturer. Therefore, we developed our own analysis strategy based on more than 1000 experiments done with the FTT using more than 100 types of fabrics.

Even though there are a number of articles relating to the FTT, none have included additional information on the handling of it, while this information is invaluable to the users in optimizing the usage of the device. Hence, this paper will discuss the best practices and practical application of the FTT for comfort evaluation. Moreover, suggestion on statistical analysis approaches and other comfort related measurements are also discussed here.

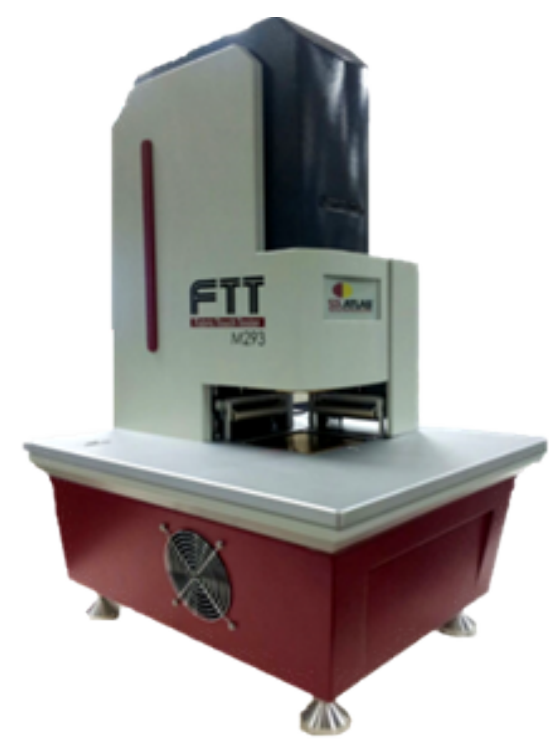

Figure 1: Fabric touch tester; source Binti Haji Musa et.al, 2017 [6]. 
Table 1: FTT indices; source Binti Haji Musa et.al, 2017 [6].

\begin{tabular}{|c|c|c|c|c|c|c|}
\hline Item & Fabric Property & Index & Description & $\begin{array}{l}\text { Unit given by FTT } \\
\text { software }\end{array}$ & SI unit & Usual interpretations \\
\hline 1 & \multirow{2}{*}{ Bending } & BAR & Bending Average Rigidity & $\mathrm{gf} \mathrm{mm} \mathrm{rad}^{-1}$ & $\mathrm{~N} \mathrm{~m} \mathrm{rad}-1$ & Force needed to bend per radian \\
\hline 2 & & BW & Bending Work & gf $\mathrm{mm}$ rad & $\mathrm{N}$ m rad & Work needed to bend \\
\hline 3 & Surface friction & SFC & Surface Friction Coefficient & - & - & $\begin{array}{l}\text { Friction coefficient on surface with ribbed } \\
\text { plate }\end{array}$ \\
\hline 4 & \multirow{2}{*}{ Surface roughness } & SRA & $\begin{array}{l}\text { Surface Rough-ness } \\
\text { Amplitude }\end{array}$ & $\mu \mathrm{m}$ & $\mathrm{m}$ & Roughness irregular wave amplitude \\
\hline 5 & & SRW & $\begin{array}{l}\text { Surface Rough-ness } \\
\text { Wavelength }\end{array}$ & $\mathrm{mm}$ & $\mathrm{m}$ & Roughness irregular wave wavelength \\
\hline 6 & \multirow{5}{*}{ Compression } & $\mathrm{CW}$ & Compression Work & gf $\mathrm{mm}$ & $\mathrm{N} \mathrm{m}$ & Work needed to compress the specimen \\
\hline 7 & & CRR & Compression Recovery Rate & - & - & $\begin{array}{l}\text { Percentage of thickness changes after } \\
\text { compressed }\end{array}$ \\
\hline 8 & & CAR & $\begin{array}{l}\text { Compression Average } \\
\text { Rigidity }\end{array}$ & $\mathrm{gf} \mathrm{mm}^{-3}$ & $\mathrm{~N} \mathrm{~m}^{-3}$ & Forces needed to compress per $\mathrm{mm}$ \\
\hline 9 & & RAR & Recovery Average Rigidity & $\mathrm{gf} \mathrm{mm}^{-3}$ & $\mathrm{~N} \mathrm{~m}^{-3}$ & Forces reflected when recovery per mm \\
\hline 10 & & $\mathrm{~T}$ & Thickness & $\mathrm{mm}$ & $\mathrm{m}$ & Thickness of the materials \\
\hline 11 & \multirow{3}{*}{ Thermal conductivity } & TCC & $\begin{array}{l}\text { Thermal Conductivity under } \\
\text { Compression }\end{array}$ & $10^{-3} \mathrm{~W} \mathrm{~m}^{-1}{ }^{\circ} \mathrm{C}^{-1}$ & $\mathrm{~W} \mathrm{~m}^{-1}{ }^{\circ} \mathrm{C}^{-1}$ & $\begin{array}{l}\text { Energy transmitted per degree per } \mathrm{m} \text { per } \\
\text { second under specimen compression }\end{array}$ \\
\hline 12 & & TCR & $\begin{array}{l}\text { Thermal Conductivity under } \\
\text { Recovery }\end{array}$ & $10^{-3} \mathrm{~W} \mathrm{~m}^{-1}{ }^{\circ} \mathrm{C}^{-1}$ & $\mathrm{~W} \mathrm{~m}^{-1}{ }^{\circ} \mathrm{C}^{-1}$ & $\begin{array}{l}\text { Energy transmitted per degree per } \mathrm{m} \text { per } \\
\text { second under specimen recovery }\end{array}$ \\
\hline 13 & & Qmax & Thermal Maximum Flux & $\mathrm{W} \mathrm{mm}^{-2}$ & $W \mathrm{~m}^{-2}$ & $\begin{array}{l}\text { Maximum energy trans-mitted during } \\
\text { compression }\end{array}$ \\
\hline
\end{tabular}

\section{Handling of FTT}

The way to handle the FTT has been concisely described in the manual provided by the manufacturer. Here we report additional information which is useful. First and foremost, we would like to emphasize what to do before the real test takes place. Sample preparation is the most important. Similar to common procedures, the samples need to be conditioned in the standard atmosphere at $20^{\circ} \mathrm{C} \pm 2^{\circ} \mathrm{C}$ with $65 \% \pm 4 \%$ relative humidity [3]. As stated in the manual document, the sample should be in an L shape with a said dimension. It is advisable to clearly note the direction of the fabric (warp/weft or wale/course) and also the sides (outside/inside) before cutting. Cutting procedure is best to be conducted using a pressure cutting machine with an L shape mould specifically tailored for this test.

For every batch of fabric sample, it is highly recommended to first perform a sensor check. Start with the self-check command which can be found under the 'run' menu bar. After this test is finished, all the indicators in the pop-up window should appear in green color if the sensors are working well within the specified range. The device is useful when the sensors are in good working condition. The selfcheck command is not sufficient for this in our opinion. Hence, we have initiated another method to check the functionality of the sensors, to ensure that all sensors in the two directions (warp and weft) of the test are coherent. The test is called single leg test, where one performs a preliminary test using rectangular strips of standard yellow samples provided by the manufacturer, instead of the usual L shape in the real test. The test is done five times in each direction's. During the measurement, while one direction is fed by the sample, one is left bare. Hence, one can verify that the sensors give a 0 value for this unused direction. If not, it means that the sensors are picking up other values which will make them incompetent for the actual test. The manufacturer has stated the values of $\mathrm{BW}=580, \mathrm{~T}=0.63, \mathrm{Qmax}=980$ and $\mathrm{SFC}=0.3$ with tolerance of $10 \%$ for the standard yellow sample, which is used to verify the validity of the single leg test. It is advisable to create extra reference samples, which are best woven samples to generally represent the fabrics.
Since the FTT is not provided with a zero point thickness calibration, we recommend a further simple calibration method. Run the FTT without any sample in order to see what are the values it picks up and next use several rigid bodies (plates) for which FTT is expected to give consistent values. The plates could be a square of $11 \times 11 \mathrm{~cm}$ and placed on the bottom plate of the FTT where the compression sensor will do the measurement. Small deviation of less than $0.02 \mathrm{~mm}$ can be tolerated. In our experience, if the deviations in thickness measurement are more than $0.02 \mathrm{~mm}$ on rigid bodies, it can be resolved by extensive cleaning using water and non-abrasive towel for the lower and upper FTT plates. This device relies on its sensors for the measurement. Hence, it is necessary to put extra attention on checking the reliability of the sensors to ensure the obtained results can be trusted.

A typical use of the FTT is to compare comfort of samples, e.g. 10 samples A and 10 samples B, of which 5 are used for each side. The official use of the FTT is then to test sample A first, obtain a comfort fingerprint, then sample B, each with their own FTT (.ftt) file, and compare the results. However, samples of a batch should be tested randomized so as to avoid time based effects. This means that samples of A and B will be tested in a mixed fashion, and only afterward we extract and analyze the different sample sets. It is then a good practice to create a spreadsheet $\log$ file for every batch of samples that is tested. The log file should contain the corresponding sample name as in the FTT (.ftt) file, sample type and number, sides of the fabric and additional information such as date and the name of the operator. These are really useful for future references. It is also recommended to test 10 samples for each type and side of the fabric. Although the current guidelines suggest only five, based on our experience, 10 is the minimum to be sufficient to run the statistical analysis later on.

Finally, the FTT contains a hot plate, which heats up during testing. Normally, thin woven fabric would raise the temperature quicker than knitted and thick ones. Hence, once the bottom plate reaches $10^{\circ} \mathrm{C}$ above the room temperature, one should allow the plate to cool down, so as to avoid temperature dependent changes in the textile. 


\section{FTT Data Analysis}

Once the test is finished, an index report can be generated from the software. This report consists of the whole 13 FTT fabric indices data in .xls format. By using python statsmodels package or a likewise powerful statistical package, both log file that was suggested earlier, and the index report can be merged to allow further statistical analysis to be performed on the dataset. During the merge, an extra column is added with the sample type (e.g. A or B) and sample number (for more advanced analysis, columns corresponding to the design of experiments (DOE) can be added). First and foremost, the outliers must be removed from the dataset and only the value within the interquartile range (IQR) should be retained. This is required as several sensors will contain large outliers which otherwise would overshadow the results. Means, standard deviation and standard error of the data can be easily calculated and can be visualized through boxplots and bar charts to aid the readers to spot any obvious differences in the dataset. The most important test would be analysis of variance (ANOVA) which is used to analyze the differences of the fabric means, thus the main results for each index could be implicitly interpreted. Prior ANOVA, Levene's test is suggested to be done to ensure the equality of variance as ANOVA can only be useful if the variances are equal. Since FTT software can also yield the comfort indices i.e. smoothness, softness and warmth and also two global comfort indices i.e. total hand and total touch, we can transform it in a radar plot as plots are much easier to comprehend than figures. Note that in the case of outliers, the computed comfort indices are not usable and must be discarded. Ideally, one should use a custom designed comfort model geared towards the fabrics tested, which allows to adapt the model as needed. For example, the standard comfort indices are not usable when testing textured fabrics due to their dependence on roughness wavelength and amplitude data, which only are usable on homogenous surface fabrics.

When doing tests on new types of fabric, one should always try to find a connection between the given results and other measurements. For instance, panel tests; which are always favored by companies as it gives a direct idea on how the human would perceive/feel the fabric and whether the FTT comfort models predicts the same as a human being or not. Then, correlation analysis can be done to determine the relationship between FTT indices and the panel test. These results are very important as they could verify the primary comfort models used in the FTT software. For instance, we found that these models are suitable for some mattress ticking fabrics, however they were not suitable for some knitted fabrics differentiated by spinning methods. These findings prove the complexity of fabric hand assessment both by instruments and panels. A correct subjective assessment is particularly complex especially with high number of fabrics with special textures. Therefore, a comprehensive testing protocol is needed to achieve a good and reliable result.

Other objective tests that can be used to compare with the FTT are the Tissue Softness Analyzer (TSA), Kawabata Evaluation System for fabric (KESF), handle-o-meter and ring-o-meter. A study by Abu Rous et al. [5] denoted that FTT prediction of softness and softness were in good agreement with other objective methods as well as the expert panels. In our own experience, KESF measures with different modules which have no 1-1 correspondence to the FTT measurements, while resulting softness provided by instruments such as handle-o-meter, ring-o-meter and TSA globally corresponded with the FTT softness results. FTT may also be employed to assess the influence of some variables in production parameters on fabrics properties through design of experiment (DOE). Statistical software (i.e. JMP by SAS) can be used for generating a DOE and statistical interpretation of the results. Such software tool allows reliable results while testing a limited number of fabrics developed according to combination of the continuous or categorical production parameters (i.e. fabric mass per surface area, type of raw material, etc.) considered [8]. These statistical analysis procedures suggest that the FTT data can be used and explained in many ways that could benefit the users.

\section{FTT Highlights}

Based on our findings through numerous experiences in working with the FTT, we can state that this is the one and only device of its kind that can measure handle properties of fabric within five minutes per sample, comprehensively for warp and weft, outside and inside. However, the predicted comfort models are observed to be more suitable for clothing fabrics, making it less suitable for technical fabrics, spacer, terry or automotive fabrics. This might be due to the limited range of fabrics tested by the manufacturer to generate the comfort models. Since the FTT comfort models are meant only for a specific set of fabrics, other prediction models are required for those fabrics not included in the range, and these should be custom designed by the user.

Even so, a variety of clothing fabrics can be tested with this device. The research highlights that this tool can discriminate between samples with small differences induced by fabric treatment [7], fiber content [5] or production settings [4] although in some cases the panels were not even able to distinguish them. However, the results should be carefully interpreted in the event of thicker fabrics, terry and fabrics with irregular surface patterns as part of the results might be unusable. Moreover, thin knitted fabrics may also cause problems, particularly those with curled or rolled edges as they are difficult to be correctly positioned on the device platform, thus making the results less trusted.

\section{Conclusion}

A new device, FTT is claimed by its manufacturer as a device that can rapidly measure fabric comfort properties within its four integrated modules, i.e. thermal, compression, surface and bending. No standard yet exists; thus the handling methods are just based on the manufacturer's manual guidelines. An extensive usage of this device gives us some additional input that might be useful for other FTT users as these have not been publicly shared by the manufacturer yet.

The content of this paper focuses on the extended information regarding the handling of the device, some suggestions on how to analyze the data using statistical analysis methods, and also highlights of the key features and pitfalls to avoid in using the FTT for comfort measurement. The emergence of this device brings simplicity to the testing protocol of the comfort properties of clothing fabrics within a certain range. After all, the complexity of the human tactile perception is really challenging so that the "one model or one equipment fits all concept" does not apply for the measurement of fabric comfort.

\section{Acknowledgement}

We would like to acknowledge the Ministry of Education, Malaysia and Universiti Teknologi MARA, Malaysia for the sponsorship given for the study. The results are obtained within the international ERANET-CORNET project - IWT 140387 (2015-2016) named Touché. 
Citation: Binti Haji Musa A, Malengier B, Vasile S, Van Langenhove L (2018) Practical Considerations of the FTT Device for Fabric Comfort Evaluation. J Fashion Technol Textile Eng S4:003.

\section{References}

1. Hu JY, Hes L, Li Y, Yeung KW, Yao BG (2006) Fabric Touch Tester: Integrated evaluation of thermal-mechanical sensory properties of polymeric materials Polym Test 25: 1081-1090.

2. Liao X, Li Y, Hu J, Wu X, Li Q (2014) A simultaneous measurement method to characterize touch properties of textile materials. Fibers Polym 15: 15481559.

3. SDL Atlas (2014) Rycobel. Fabric Touch Tester.

4. Vasile S, Malengier B, De Raeve A, Louwagie J, Vanderhoeven M (2016) Assessment of sensorial comfort of fabrics for protective clothing.
5. Abu Rous M (2016) Handle properties of fabrics made of wood-based fibers: Softness and smoothness of textiles.

6. Binti Haji Musa A, Malengier B, Vasile S, Van Langenhove L, De Raeve A (2017) Analysis and Comparison of Thickness and Bending Measurements from Fabric Touch Tester (FTT) and Standard Methods.

7. Vasile S, Malengier B, De Raeve A, Binti Haji Musa A (2017) FTT comfort indices of ring spun and air-jet knitted fabrics with post-treatments.

8. Vasile S, Malengier B, Deruyck F, De Raeve A (2017) Influence of selected production parameters on the hand of mattress knitted fabrics assessed by Fabric Touch Tester FTT. Text Res J.

\section{Author Affiliations}

${ }^{1}$ Department of Materials, Textiles and Chemical Engineering, Centre for Textile Science and Engineering Ghent University, Belgium

${ }^{2}$ Department of Fashion, Textile and Wood Technology, University College Ghent, BE-9051 Gent, Belgium

${ }^{3}$ Universiti Teknologi MARA Cawangan Negeri Sembilan, Kampus Kuala Pilah, Negeri Sembilan, Malaysia

Submit your next manuscript and get advantages of SciTechnol submissions

* 80 Journals

* 21 Day rapid review process

* 3000 Editorial team

* 5 Million readers

- More than 5000

* Quality and quick review processing through Editorial Manager System

Submit your next manuscript at • www.scitechnol.com/submission 